\title{
USing Markov Analysis to StUdy THE IMPACT OF TEMPERATURE IN BANGLADESH
}

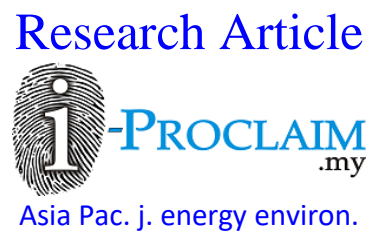

\author{
Janardan Mahanta ${ }^{1^{*}}$, Soumen Kishor Nath ${ }^{2}$, Md. Haronur Rashid ${ }^{3}$ \\ ${ }^{1}$ Assistant Professor, Department of Statistics, University of Chittagong, Chittagong, BANGLADESH \\ ${ }^{2}$ Assistant Professor, Institute of Education and Research, University of Chittagong, Chittagong, BANGLADESH \\ ${ }^{3}$ Research Student, Department of Statistics, University of Chittagong, Chittagong, BANGLADESH \\ *Email for Correspondence: johnstat@cu.ac.bd
}

Key words

Temperature, Markov Chain

\begin{tabular}{|ll}
\hline 7/16/2019 & Source of Support: None | No Conflict of Interest: Declared \\
\hline $\begin{array}{l}\text { This article is is licensed under a Creative Commons Attribution-NonCommercial } 4.0 \text { International License. } \\
\text { Attribution-Non Commercial (CC BY-NC) license lets others remix, tweak, and build upon work non-commercially, and although the new works must also } \\
\text { acknowledge \& be non-commercial. }\end{array}$ CC) 8 NC
\end{tabular}

\section{INTRODUCTION}

Global warming becomes one of the most important environmental problems in the $21^{\text {st }}$ century, the impacts of global warming are worldwide (Chan, 2006) and Bangladesh is one of the most vulnerable countries in the world. The assumption that increased green house gas concentrations may lead to a rise in global temperatures first an emerged in the 1960s (Peterson et al., 2008). The great majority of climate scientists now agree that the evidence for anthropogenic warming is strong (Rosenberg et al., 2010). Predication of average temperature changes and the economic costs of climate change are uncertain but generally bleak: for increases of $5^{\circ} \mathrm{C}-6^{\circ} \mathrm{C}$, which is a "production as usual" scenario, the predicted economic lose is $5-10 \%$ of global GDP (Stern, 2007). The consequences of climate change becoming increasingly ineluctable and are drawing the attention of decision around the world. It is already obvious that few social and economic lives will remain unaffected. Climate change is likely to have repercussions for development, human rights protection and security, to mention but a few. Among the most significant impacts of climate change are those on human mobility. Estimates vary widely figures ranging between 25 million and 1 billion people displaced by climate change over the next 40 years. While the magnitude may be uncertain, the actual impact on people is not.

The central idea of this workshop is that migration in the context of climate change can be both problem and solution. On the other hand, the serious humanitarian consequence of environment migration cannot be ignored.

Bangladesh is the most populated country in the world. The country is over populated in the context of its area and natural resources and is a victim of frequent natural hazards like cyclones, tornadoes, floods and storm. Bangladesh is located in a very difficult area of the world.

Many of the anticipated adverse effects of climate change, such as sea level rise, higher temperatures enhanced monsoon precipitation and an increase in cyclone intensity will aggravate the existing stress that already impede development in Bangladesh, particularly by reducing water and food security and damaging essential infrastructure. These impacts could be extremely detrimental to the economy, the environment, national development and the people of Bangladesh. 
Bangladesh has developed some capacity for dealing with the impacts of climate change at the national level and policy response options have been mobilized that deal with vulnerability reduction to environment variability in general, and more recently, to climate change in particular. In addition, Bangladesh has been recognized as a particularly vulnerable country, and adaptation support in several sectors.

This briefing will begin by describing the country characteristics of Bangladesh that make it particularly vulnerable to climate change, before outlining the main climate change influences that are concern to Bangladesh. These impacts will then be discussed in relation to their adverse effects on different sectors. Finally, the national and international policy responses to variability in general, as well as those that target climate change specifically.

The potential increase in temperature has a significant impact on crop productivity. Every year has a significant impact on productivity. Every year a huge amount of rice production is lost due the increasing temperature that eventually threatens the food security in Bangladesh. It has been assessed that in the year 2020, 2030, 2040, 2050. There will be a considerable yield reduction $(1.5 \%, 2.5 \%, 4.4 \%, 5.4 \%$ respectively). This will directly affect the total rice production in the country and at the same time economy of Bangladesh.

Increasing temperature also has an apparent negative effect on human health. Heat stress reduces labor capacity considerable and as temperature raises the frequency of heat-related condition such as hypoxia and heat stroke increases. The higher temperature has increased connections of ground level ozone, which is the reason for many respiratory conditions (Sahney et al., 2010).

Temperature is important atmospheric components and has significant influence on climate change. This article using the technique of Markov chain has been estimated future temperature status.

\section{Methodology}

This article has been used temperature data taken from "Bangladesh Metrological Department" Climate Division, Agargaon in Dhaka. Two stations such as Dhaka in period 2003-2013 and Chittagong in 2008-2013 have been taken.

\section{Dhaka}

Dhaka is the capital city of Bangladesh and the principal city of Dhaka district. Located on the banks of the Buriganga River. The population is over 18 million in the in greater Dhaka area, making its largest city in Bangladesh and one of the most populations in the world.

\section{Chittagong}

The port city in Chittagong is the second largest city in Bangladesh. It is situated in the southeastern portion of the country and was built on the banks of the Karnaphuli River. Nestled between the Chittagong hill tracks and the Bay of Bengal, Chittagong is a major commercial center and busiest seaport. The Chittagong is a hilly area, has lower maximum and minimum temperatures than other parts of the country.

The prompt development of computer and information technology makes the procedure of analyzing data easier. Now a day, none can thing to analyze data without a suitable computer program. To analyze the data quickly, easily and correctly has no alternate of computer program. Microsoft Excel, SPSS, and R programming have been used in the article.

\section{Comparative Means Analysis}

A summary of temperature has been presented in table (1-4) in the Dhaka and Chittagong stations.

Table 1: Seasonally comparative means analysis of Dhaka station (2003-2013)

\begin{tabular}{lcccc}
\hline Season & Mean & Std. Deviation & Minimum & Maximum \\
\hline Pre-monsoon & 33.5259 & 2.4090 & 22.4000 & 39.6000 \\
\hline Monsoon & 32.4407 & 1.9255 & 24.6000 & 36.7000 \\
\hline Post-monsoon & 31.1916 & 2.2706 & 21.2000 & 36.5000 \\
\hline Winter & 26.1571 & 3.2788 & 13.4000 & 35.9000 \\
\hline
\end{tabular}

Table 1 represent that, the average temperature of pre-monsoon, monsoon, post-monsoon and winter season is $33.52^{\circ}$ $\mathrm{C}, 32.44^{\circ} \mathrm{C}, 31.19^{\circ}$ and $26.15^{\circ} \mathrm{C}$ respectively and high and low temperature have been shown pre-monsoon and winter season respectively. 
Table 2: Yearly comparative means analysis of Dhaka station (2003-2013)

\begin{tabular}{ccccc}
\hline Year & Mean & Std. Deviation & Minimum & Maximum \\
\hline 2003 & 30.2233 & 4.0314 & 13.4000 & 36.7000 \\
\hline 2004 & 30.5145 & 3.6673 & 15.1000 & 38.1000 \\
\hline 2005 & 30.8279 & 3.4409 & 18.8000 & 37.0000 \\
\hline 2006 & 31.2693 & 3.3086 & 16.2000 & 38.5000 \\
\hline 2007 & 30.5534 & 3.8082 & 18.1000 & 37.5000 \\
\hline 2008 & 30.5721 & 3.8911 & 17.7000 & 36.9000 \\
\hline 2009 & 31.6077 & 3.5012 & 21.1000 & 39.6000 \\
\hline 2010 & 31.4170 & 3.9060 & 16.1000 & 37.9000 \\
\hline 2011 & 30.5789 & 3.8829 & 14.2000 & 36.2000 \\
\hline 2012 & 30.8284 & 4.0869 & 15.7000 & 37.3000 \\
\hline 2013 & 30.9532 & 3.7233 & 15.0000 & 37.1000 \\
\hline
\end{tabular}

Maximum temperature occurred in 2009 which is $39.60^{\circ} \mathrm{C}$ and minimum temperature observed in 2003 that is $13.4^{\circ} \mathrm{C}$.

Table 3: Seasonally Comparative means analysis of Chittagong station (2008-2013)

\begin{tabular}{lcccc}
\hline Season & Mean & Std. Deviation & Minimum & Maximum \\
\hline Pre-monsoon & 31.4333 & 1.6030 & 25.4000 & 36.3000 \\
\hline Monsoon & 30.8822 & 1.7821 & 25.5000 & 36.5000 \\
\hline Post-monsoon & 30.5143 & 1.8634 & 24.5000 & 35.0000 \\
\hline Winter & 26.5310 & 2.7063 & 16.4000 & 33.3000 \\
\hline
\end{tabular}

Average temperature $31.43^{\circ} \mathrm{C}, 30.88^{\circ} \mathrm{C}, 30.51^{\circ} \mathrm{C}$ and $26.53^{\circ} \mathrm{C}$ have been observed in pre-monsoon, monsoon, postmonsoon and winter season respectively in Chittagong.

Table 4: Yearly comparative means analysis of Chittagong station (2008-2013)

\begin{tabular}{ccccc}
\hline Year & Mean & Std. Deviation & Minimum & Maximum \\
\hline 2008 & 29.4978 & 2.7868 & 19.0000 & 34.3000 \\
\hline 2009 & 30.2896 & 2.5056 & 23.2000 & 35.0000 \\
\hline 2010 & 30.2742 & 2.8775 & 19.5000 & 36.3000 \\
\hline 2011 & 29.5773 & 2.9178 & 16.4000 & 34.4000 \\
\hline 2012 & 29.7456 & 2.8740 & 19.4000 & 34.8000 \\
\hline 2013 & 29.7375 & 2.7432 & 18.5000 & 36.5000 \\
\hline
\end{tabular}

In Chittagong $36.50^{\circ} \mathrm{C}$ maximum temperature observed in 2013 when average maximum temperature $30.29^{\circ} \mathrm{C}$ was observed in 2009.

By analyzing the above table, it is seen that average temperature of Dhaka are higher than Chittagong that have been occurred in pre-monsoon season also maximum and minimum temperature are both lies in Dhaka.

\section{LINEAR REgression MODEL}

The linear regression line has been fitted using the most common method by the least squares. This method calculates the best fitting line for the observed data by minimizing the sum of the squares of the vertical deviation from each data point to the line. If a point lies exactly on the straight line then the algebraic sum of the residual is zero. Residuals are defined as the difference between an observation at a point in time and the value read from the trend line at that point in time. A point that lies far from the line has a large residual value and is known as an outlier or, an extreme value.

The equation of a linear regression line is given as

$$
y=a+b x+e
$$

Where,

$\mathrm{y}$ is the observation on the dependent variable which is temperature

$x$ is the observation on the independent variable that is time

' $a$ ' is the intercept of the line on the vertical axis and ' $b$ ' is the slope of the line and e is the error term.

By the method of least squares, the estimate of intercept ' $a$ ' and the regression coefficient ' $b$ ' are given below.

$$
\text { i.e. } \hat{a}=\bar{y}-\hat{b} \bar{x} \text { and } \hat{b}=\frac{\sum(x-\bar{x})(y-\bar{y})}{\sum(x-\bar{x})^{2}} \text {. }
$$


In order to fit regression lines of the temperature yearly average temperature (dependent variables) on time (independent variables) in years have been estimated.

For the Dhaka station the trend line is

$$
\hat{y}=30.549+0.0501 x
$$

Where, $\hat{a}=30.549, \hat{b}=0.0501$ and $R^{2}=0.1509$

In addition, For the Chittagong station the trend line is

$$
\hat{y}=29.967+0.0323 x
$$

Where, $\hat{a}=29.967, \hat{b}=0.0307$ and $R^{2}=0.0307$

The trend line represents the increasing trend that means that the temperature is increasing day by day in both Dhaka and Chittagong.

\section{MARKOV MODEL}

Consider a stochastic process $X(t)(t=1,2, \ldots \ldots)$ that takes on a finite number of states $k$. in general, the process $X(t)$ is in state $s=1,2, \ldots \ldots, k$ at the time $t=n$ if $X(n)=s$.

Let $s(t)$ denote the observed state of the stochastic process at time $t$.

For example, the initial state of the stochastic process is represented by $\mathrm{X}(\mathrm{t}=1)=\mathrm{s}(\mathrm{t})$. In this application, the process $X(t)$ has three states, namely $X(t)=1$ if the observed day is low temperature, $X(t)=2$ if the observed day is medium temperature and $X(t)=3$ if the observed day is high temperature. Temperature have been classified by low $\left(<20^{\circ} \mathrm{C}\right)$, Medium $\left(20^{\circ} \mathrm{c}-30^{\circ} \mathrm{C}\right)$ and High $\left(>30^{\circ} \mathrm{C}\right)$. Furthermore, suppose that for all $\mathrm{t}=1$, the Markov property holds, that is,

$$
\begin{aligned}
P & (X(t+1)=s t+1 \mid X(t)=s t, X(t-1)=s t-1, \ldots \ldots, X(2)=s 2, X(1)=s 1) \\
& =P(X(t+1)=s t+1 \mid X(t)=s t)
\end{aligned}
$$

In words, this property states that the probability of being in state $s t+1$ at time $t+1$ depends only on the current state st. As related to this example, observation of a significant tomorrow's temperature condition depends only on whether (or not) a significant temperature condition is observed today and not on earlier temperature condition. This model thus incorporates the dependence of tomorrow's temperature depend on today's observed temperature to inform the probability of observing a significant temperature tomorrow.

The three states transition probability matrix is given below.

\section{Next day}

$$
1 \quad 2 \quad 3
$$

$\begin{array}{ll}\text { Current day } & \mathbf{1} \\ \mathbf{2} \\ \mathbf{3}\end{array}\left[\begin{array}{lll}p_{11} & p_{12} & p_{13} \\ p_{21} & p_{22} & p_{23} \\ p_{31} & p_{32} & p_{33}\end{array}\right]$

This chain dependent process is irreducible, since every state communicates to each other. With ergodic states $1,2,3$ the Markov chain $\left(X_{n}\right)$ is said to be of order $\mathrm{k}(\mathrm{k}=1,2,3,4 \ldots)$ for all $\mathrm{n}$, if and only if,

$$
p_{i j k}=\operatorname{prob}\left(X_{n}=k / X_{n-1}=j, X_{n-2}=i\right) ; \quad \forall i, j, k=1,2,3
$$

Then $p_{i j k}$ is called a Markov chain of order two, Similarly the Markov chain of order three, four and so on can be defined.

\section{M.L. Estimation OF PARAmeters}

Anderson and Goodman (1957) continued to the development of the statistical inference for Markov chain. Suppose that the states be $\mathrm{j}=1,2,3$ and the time points of observations be $\mathrm{t}=1,2 \ldots \mathrm{T}$. let $p_{j k}(t),(\mathrm{k}=1,2,3)$ be the probability of state $\mathrm{k}$ at time $\mathrm{t}$, given that the state $\mathrm{j}$ at time $(\mathrm{t}-1)$. If $p_{j k}(t)$ is stationary, then $p_{j k}(t)$ is stationary, then $p_{j k}(t)=p_{j k}$, for all $t$, otherwise it is non-stationary. 
Let us consider a Markov chain with stationary transition probabilities $p_{j k}(\mathrm{j}=1,2,3)$ and finite number of states $(1,2$, 3). Let $n_{j k}$ be the number of observation in transition from the state $\mathrm{j}$ to the state $\mathrm{k}$.

The total number of observation is $\sum_{j=l}^{3} \sum_{k=1}^{3} n_{j k}$, where, $\mathrm{j}, \mathrm{k}=1,2,3$

$$
\sum_{k=1}^{3} n_{j k}=n_{j .} \text { and } \sum_{j=1}^{3} n_{j k}=n_{. k}
$$

Whittle (1955) noted that the observation Markov chain model from a set of independent multinational trails. He has obtained the exact probability density of the observed $n_{j k}$

$$
f\left(n_{i j}\right)=T\left(n_{i j}\right) \frac{\prod_{j}\left(n_{j .}\right) !}{\prod_{j k} \prod_{k}\left(n_{i j}\right) !} \prod_{j} \prod_{k} p_{j k}^{n_{j k}}
$$

The factor $T\left(n_{j k}\right)$ is the joint probability density of $n_{j}{ }^{\prime} s$ and is independent of $p_{j k}{ }^{\prime} s$. If we consider a Markov chain model with non-stationary transition probabilities $p_{j k}(t)$ then the probability density of $n_{j}(t)$ is given by

$$
f\left\{n_{j k}(t)\right\}=T\left\{n_{j k}(t)\right\} \frac{\prod_{j}\left\{n_{j .}(t)\right\}}{\prod_{j} \prod_{k}\left\{n_{j k}(t)\right\} !} \prod_{j} \prod_{k} p_{j k}^{n_{j k}}(t)
$$

In case of non-stationary transition probabilities, the set $\sum_{t=1}^{T} n_{j k}=n_{j k}(t)$

From a set of sufficient statistics and in the case of non-stationary transition probabilities $p_{i j k}(t)$.The set $n_{i j k}(t)$ from a multinational set of sufficient statistics.

Medhi (1984) obtained the logarithm of likelihood function for stationary transition probabilities $p_{i j k}$ as,

$$
L\left(p_{j k}\right)=C+\sum_{j=l k=1}^{3} \sum_{j k}^{3} n_{j o g} p_{j k}
$$

The factors $C$ contains all terms that are independent of $p_{i j k}$. The maximum likelihood estimates of $p_{i j k}$ are found to be

$$
\hat{p}_{j k}=\frac{n_{j k}}{n_{j}}
$$

For non-stationary transition probabilities, the maximum likelihood estimates are

$$
\hat{p}_{j k}(t)=\frac{n_{j k}(t)}{n_{j .}(t)}=\frac{n_{j k}(t)}{n_{j .}(t-1)}
$$

Thus, we may estimate the transition probabilities of Markov model. The M.L estimates for the transition probabilities of daily temperature occurrences for Dhaka and Chittagong stations have been shown in following table.

Table 5: Transition probability matrix for temperature of Dhaka station

$$
\text { Next day }
$$

123

$\left.\begin{array}{ll}1 \\ 2 \\ 3\end{array}\right]\left[\begin{array}{ccc}0.473 & 0.368 & 0.157 \\ 0.012 & 0.824 & 0.162 \\ 0.001 & 0.083 & 0.915\end{array}\right]$

The probability 0.473 indicates that current day temperature is low and next day temperature will be low that probability is 0.473 . Current day's temperature is low, which will become high in next day that probability is 0.157 . The value 0.915 means that next day will be high temperature when current day is also high temperature with probability 0.915 . In similar way, all the transition probabilities may be concluded. 
Table 6: Transition probability matrix for temperature of Chittagong station Next Day

1

Current day

$\mathbf{2}$
$\mathbf{3}$$\quad\left[\begin{array}{l}0.250 \\ 0.003 \\ 0.000\end{array}\right.$

2

0.250

0.811

0.145
3

$\left.\begin{array}{l}0.500 \\ 0.185 \\ 0.854\end{array}\right]$

Current day's temperature is high, which will become high temperature in next day that probability is 0.854 . The probability 0.250 indicates that current day temperature is low next day temperature will also be low that probability is 0.250 . The value 0.003 indicates that next day will be low temperature when current day is medium temperature with probability 0.003 . The remaining transition probabilities have been interpreted in similar way.

\section{Long RUn BehaVior of Transition Probabilities}

Feller (1957) developed the unit step, ....., m-step transition probabilities by the Chapman and Kolmogorov equation.

The Chapman-Kolmogorov equation is given

$$
p_{j k}^{m+n}=\sum_{i} p_{i k}^{(n)} p_{j i}^{(m)}=\sum_{i} p_{j i}^{(n)} p_{i k}^{(m)}
$$

For all $\mathrm{i}, \mathrm{j}, \mathrm{k}=1,2,3$

Where, $\mathrm{m}$ and $\mathrm{n}$ denote the $\mathrm{mth}$ step and $\mathrm{nth}$ step respectively.

The unit-step transition probabilities denoted by $p_{j k}$ are defined as nth probability of occurrences at the nth probability of occurrence at the nth given occurrence at the (n-1)th step.

The $2^{\text {nd }}$ step transition probabilities $p_{j k}^{(2)}$ are defined as

$$
p_{j k}^{(2)}=\operatorname{prob}\left(x_{n+2}=k / x_{n}=j\right)
$$

Therefore, the mth steps transition probabilities are

$$
p_{j k}^{(m)}=\operatorname{prob}\left(x_{n+m}=k / x_{n}=j\right)
$$

Hence, the Chapman-Kolmogorov equation has been applied to analyze the limiting behavior of daily temperature occurrences for the selected stations and the results are shown below.

Using the information from table 5 have been computed the distribution of daily temperature after $\mathrm{n}$ days which is

\begin{tabular}{|c|c|c|c|c|c|c|}
\hline \multirow{3}{*}{$\begin{array}{c}\text { After } \mathrm{n} \\
\text { days }\end{array}$} & \multicolumn{3}{|c|}{ Initial probability $\left[\begin{array}{lll}1 & 0 & 0\end{array}\right]$} & \multicolumn{3}{|c|}{ Initial probability $\left[\begin{array}{lll}0.3 & 0.3 & 0.4\end{array}\right]$} \\
\hline & \multicolumn{3}{|c|}{ Temperature } & \multicolumn{3}{|c|}{ Temperature } \\
\hline & Low & Medium & High & Low & Medium & High \\
\hline Day 0 & 1 & 0 & 0 & 0.3 & 0.3 & 0.4 \\
\hline Day 1 & 0.4730 & 0.3680 & 0.1570 & 0.1459 & 0.3908 & 0.4617 \\
\hline Day 2 & 0.2283 & 0.4903 & 0.2775 & 0.0742 & 0.4140 & 0.5087 \\
\hline Day 3 & 0.1141 & 0.5111 & 0.3692 & 0.0406 & 0.4107 & 0.5442 \\
\hline Day 4 & 0.0605 & 0.4938 & 0.4386 & 0.0247 & 0.3985 & 0.5708 \\
\hline Day 5 & 0.0350 & 0.4655 & 0.4908 & 0.0170 & 0.3848 & 0.5907 \\
\hline Day 6 & 0.0226 & 0.4372 & 0.5300 & 0.0133 & 0.3724 & 0.6055 \\
\hline Day 7 & 0.0165 & 0.4126 & 0.5593 & 0.0113 & 0.3620 & 0.6164 \\
\hline Day 8 & 0.0133 & 0.3924 & 0.5812 & 0.0103 & 0.3536 & 0.6245 \\
\hline Day 9 & 0.0116 & 0.3765 & 0.5974 & 0.0098 & 0.3470 & 0.6303 \\
\hline Day 10 & 0.0106 & 0.3641 & 0.6095 & 0.0094 & 0.3418 & 0.6345 \\
\hline Day 11 & 0.0100 & 0.3545 & 0.6183 & 0.0092 & 0.3378 & 0.6374 \\
\hline Day 12 & 0.0096 & 0.3471 & 0.6248 & 0.0090 & 0.3346 & 0.6394 \\
\hline Day 13 & 0.0093 & 0.3414 & 0.6294 & 0.0089 & 0.3321 & 0.6406 \\
\hline Day 14 & 0.0091 & 0.3370 & 0.6327 & 0.0088 & 0.3301 & 0.6414 \\
\hline
\end{tabular}
shown in table 7 consider the initial probabilities $\left[\begin{array}{lll}1 & 0 & 0\end{array}\right]$ and $\left[\begin{array}{lll}0.3 & 0.3 & 0.4\end{array}\right]$ in Dhaka.

Table 7: Limiting behavior of daily temperature of Dhaka station 


\begin{tabular}{|c|c|c|c|c|c|c|}
\hline Day 15 & 0.0090 & 0.3335 & 0.6349 & 0.0088 & 0.3285 & 0.6417 \\
\hline Day 16 & 0.0089 & 0.3309 & 0.6364 & 0.0087 & 0.3272 & 0.6418 \\
\hline Day 17 & 0.0088 & 0.3287 & 0.6373 & 0.0087 & 0.3261 & 0.6416 \\
\hline Day 18 & 0.0088 & 0.3270 & 0.6378 & 0.0087 & 0.3252 & 0.6413 \\
\hline Day 19 & 0.0087 & 0.3256 & 0.6379 & 0.0086 & 0.3243 & 0.6408 \\
\hline Day 20 & 0.0087 & 0.3244 & 0.6378 & 0.0086 & 0.3236 & 0.6402 \\
\hline Day 21 & 0.0086 & 0.3235 & 0.6375 & 0.0086 & 0.3230 & 0.6396 \\
\hline Day 22 & 0.0086 & 0.3226 & 0.6371 & 0.0086 & 0.3224 & 0.6389 \\
\hline Day 23 & 0.0086 & 0.3219 & 0.6365 & 0.0086 & 0.3218 & 0.6382 \\
\hline Day 24 & 0.0086 & 0.3212 & 0.6359 & 0.0086 & 0.3213 & 0.6374 \\
\hline Day 25 & 0.0085 & 0.3206 & 0.6709 & 0.0085 & 0.3206 & 0.6709 \\
\hline Day 26 & 0.0085 & 0.3206 & 0.6709 & 0.0085 & 0.3206 & 0.6709 \\
\hline
\end{tabular}

Long-run distributions have not been affected by initial probabilities. After 26 (since day 0 represents first day) days the distribution will be stationary have been shown by table 7. That is current day's temperature will not be any effect after 26 days temperature. In future, in a certain day temperature will be high, medium and low with probability $0.67,0.32$ and 0.01 respectively.

From table 5, current day's temperature is high and next day will be high that probability is 0.915 . That means temperature of Dhaka is increasing day-by-day, which is alarming for us.

Using transition probability matrix have been presented in table 6, long-run distribution of daily temperature after $n$ days which have been shown in table 8 consider the initial probabilities $\left[\begin{array}{lll}1 & 0 & 0\end{array}\right]$ and $\left[\begin{array}{lll}0.3 & 0.3 & 0.4\end{array}\right]$.

Table 8: Limiting behavior of daily temperature of Chittagong

\begin{tabular}{|c|c|c|c|c|c|c|}
\hline \multirow{3}{*}{$\begin{array}{c}\text { After } \mathrm{n} \\
\text { days }\end{array}$} & \multicolumn{3}{|c|}{ Initial probability $\left[\begin{array}{lll}1 & 0 & 0\end{array}\right]$} & \multicolumn{3}{|c|}{ Initial probability $\left[\begin{array}{lll}0.3 & 0.3 & 0.4\end{array}\right]$} \\
\hline & \multicolumn{3}{|c|}{ Temperature } & \multicolumn{3}{|c|}{ Temperature } \\
\hline & Low & Medium & High & Low & Medium & High \\
\hline Day 0 & 1 & 0 & 0 & 0.3 & 0.3 & 0.4 \\
\hline Day 1 & 0.2500 & 0.2500 & 0.5000 & 0.2500 & 0.2500 & 0.5000 \\
\hline Day 2 & 0.0633 & 0.3378 & 0.5983 & 0.0759 & 0.3763 & 0.5471 \\
\hline Day 3 & 0.0168 & 0.3765 & 0.6050 & 0.0201 & 0.4035 & 0.5748 \\
\hline Day 4 & 0.0053 & 0.3973 & 0.5947 & 0.0062 & 0.4156 & 0.5756 \\
\hline Day 5 & 0.0025 & 0.4097 & 0.5841 & 0.0028 & 0.4221 & 0.5715 \\
\hline Day 6 & 0.0019 & 0.4176 & 0.5759 & 0.0020 & 0.4259 & 0.5676 \\
\hline Day 7 & 0.0017 & 0.4227 & 0.5700 & 0.0018 & 0.4282 & 0.5645 \\
\hline Day 8 & 0.0017 & 0.4259 & 0.5658 & 0.0017 & 0.4295 & 0.5622 \\
\hline Day 9 & 0.0017 & 0.4278 & 0.5628 & 0.0017 & 0.4303 & 0.5604 \\
\hline Day 10 & 0.0017 & 0.4290 & 0.5607 & 0.0017 & 0.4307 & 0.5591 \\
\hline Day 11 & 0.0017 & 0.4296 & 0.5590 & 0.0017 & 0.4308 & 0.5580 \\
\hline Day 12 & 0.0017 & 0.4300 & 0.5583 & 0.0017 & 0.4300 & 0.5583 \\
\hline Day 13 & 0.0017 & 0.4300 & 0.5583 & 0.0017 & 0.4300 & 0.5583 \\
\hline
\end{tabular}

From the above table it is clear that there is no influence of initial probability on the steady state distribution of temperature has been presented in table 8. Results have been indicated that after 13 (since day 0 represents first day) days the distribution becomes stationary that means, there is no impact between current days temperature with after 13 days temperature. In future, in a specific day 56\%, 43\% and rest temperature will be high, medium and low respectively. From the table 6 current day is high temperature will be high in next day that probability is 0.854 that means the temperature of Chittagong day by day increasing.

\section{Conclusions}

The climate change has been escalating over the centuries, causing a complete upturned impact of the ecosystem of the earth surface. The historical climate change along with the present rate of change has influenced us to project the further climate change. Because of climate change, will increase evaporate transpiration and create situations like water loss from soil, resultant reduced crop yield, and lower level of water both in surface and ground water systems, higher microbial concentration, and growth rate in the surface waters and so on. If not checked in time, the exacerbating aridity and accompanying desertification process as consequence of increased surface temperature is destined to cause severe environmental degradation in different part of the country. 
This paper analyzes the temperature data of two stations such as Dhaka and Chittagong to predict the overall condition of temperature in future. Yearly maximum and minimum temperature lies in year 2009 (39.60 $\mathrm{C}$ ) and year $2003\left(13.40^{\circ} \mathrm{C}\right)$ respectively in Dhaka. Yearly maximum and minimum temperature lies in year $2013\left(36.50^{\circ} \mathrm{C}\right)$ and year $2011\left(16.40^{\circ} \mathrm{C}\right)$ respectively in Chittagong.

Then we have analyzed the Markov chain model for long-term behavior of temperature for two different stations.

About $67.09 \%$ and 55.83\% temperature will be high in Dhaka and Chittagong stations respectively have been observed. Bangladesh should also prepare adaptation policies to minimize the adverse effect of climate change. Vulnerabilities assessment, disaster management, enhanced structure design, institutional reform and anti-extreme climate engineering are some feasible adaptation policies in Bangladesh due to increasing temperature.

\section{REFERENCES}

Anderson, T. W., \& Goodman, L. A. (1957). Statistical inference about Markov chains. The Annals Mathematical Statistics , 89-110.

Chan, J. C. (2006). Comments on "Changes in tropical cyclone number, duration and intensity in a warming environment. Science, $311,1713$.

Feller, W. (1957). An Introduction to Probability Theory and Its Applications, vol.1, 2d ed., John Wiley \& Sons, Inc., New York.

Medhi, J. (1984). Stochastic Process. New age international publishers.

Peterson, T. C., X.Zhang, M. B., \& Aguirre, J. L. (2008). Changes in North American extremes derived from daily weather data. J. Geophys. Res, 113.

Rosenberg, S., Vedlitz, A., Cowman, D., \& Zahran, S. (2010). Climate change: a profile of U.S. climate scientists perspective. Clim Chang , 101 (3-4), 663-668.

Sahney, S., Benton, M. J., \& Ferry, P. (n.d.). "Link between global taxonomic diversity, ecological diversity and the expansion of vertebrates on land". Biology Letters .

Stern, N. (2007). The economics of climate change: The Stern review. Cambridge University Press, Cambridge.

Whittle, P. (1955). Some distribution and moment formulae for the Markov chain. Journal of Royal Statistical Society , $235-242$. 